\title{
Seguimiento del precedente por los ministros de la Corte Suprema en materia laboral. Análisis empírico del recurso de unificación de jurisprudencia chileno ${ }^{1}$
}

\author{
Justices of the Supreme Court following precedent in Labor \\ Matters. Empirical Analysis of the appeal to unify chilean \\ jurisprudence
}

\author{
L. IVÁN DÍAZ GARCÍA ${ }^{2}$ \\ Universidad Católica de Temuco, Chile \\ SOFÍA ALARCÓN GARCÍA ${ }^{3}$ \\ Universidad Católica de Temuco, Chile \\ KATERINE CEMPE CEMPE 4 \\ Universidad Católica de Temuco, Chile \\ LUIS GARRIDO ESPARZA 5 \\ Universidad Católica de Temuco, Chile
}

I. Esta investigación ha sido desarrollada en el marco de la ejecución del proyecto Fondecyt I I I I 3 Io, cuyo investigador responsable es Luis Iván Díaz García.

2. Abogado. Doctor en Derecho en la Universidad Carlos III de Madrid, España. Académico en la Facultad de Ciencias Jurídicas de la Universidad Católica de Temuco, Chile, e integrante del Grupo de Investigaciones Jurídicas de la misma. Correo: <ivandiaz@uct.cl>.

3. Egresada de Derecho en la Universidad Católica de Temuco, Chile. Correo: $<$ palarcon2009@alu.uct.cl>.

4. Egresada de Derecho en la Universidad Católica de Temuco, Chile. Correo: <kcempre2009@alu.uct.cl>.

5. Egresado de Derecho en la Universidad Católica de Temuco, Chile. Correo: <lgarridoe2009@alu.uct.cl>. 
A LEJ ANDRO ZÚ Ñ G A G AR I D O ${ }^{6}$
Universidad Católica de Temuco, Chile

RECEPCIÓN: I6/O7/20I 5 •ACEPTACIÓN: I3/O8/20I 5

RESUMEN La investigación pretende evaluar el grado de seguimiento que han tenido los precedentes establecidos por la Corte Suprema al pronunciarse sobre los recursos de unificación de jurisprudencia entre los años 2008 y 20I3, por parte de los Ministros de este mismo tribunal. Esta evaluación, que se denomina «interna y personal», complementa la evaluación «interna e institucional» que se ha realizado en una investigación anterior. Los resultados demuestran que, en general, hay un muy elevado seguimiento del precedente a nivel interno y personal.

PALABRAS CLAVE Unificación de jurisprudencia, precedente, jurisprudencia, Corte Suprema, Derecho del Trabajo.

ABSTRACT The research aims to evaluate the extent to which the precedents established by the Supreme Court, by reaching a decision on the appeals to unify jurisprudence between 2008 and $20 \mathrm{I}_{3}$, have been followed by the Justices of that same court. This evaluation, which is «internal and personal», complements the «internal and institutional» evaluation that was carried out in a previous investigation. The results show that, in general, the precedent has been closely followed at an internal and personal level.

KEYWORDS Unification of jurisprudence, precedent, jurisprudence, Supreme Court, Labor Law.

\section{Introducción}

El 29 de marzo de 2008 se publicó en el Diario Oficial la Ley 20.260 que, entre otras innovaciones, incorporó al ordenamiento jurídico chileno el re-

6. Egresado de Derecho en la Universidad Católica de Temuco, Chile. Correo: <azunigag2009@alu.uct.cl>. 
curso de unificación de jurisprudencia laboral. Este medio de impugnación, de competencia exclusiva de la Corte Suprema, tuvo por objetivo uniformar la interpretación de las normas del Derecho del Trabajo. Esta pretensión sólo puede cumplirse, como con acierto expresa Couso, mediante el seguimiento del precedente establecido a través de dicho recurso. En efecto, la uniformidad jurisprudencial es resultado de una interpretación consistente de las disposiciones del ámbito laboral, lo que necesariamente implica mantener una determinada interpretación sobre la disposición legal de que se trate.

En ese contexto, y desde un punto de vista empírico, resulta inevitable preguntarse si la incorporación del recurso de unificación de jurisprudencia laboral ha producido un seguimiento del precedente. Esta pregunta, no obstante, exige diversos niveles de análisis que conviene distinguir. En efecto, el seguimiento del precedente puede ser analizado, a lo menos, desde tres perspectivas: por una parte, en un sentido interno e institucional, por otra parte en un sentido interno y personal y por último en un sentido vertical. Con las dos primeras perspectivas se pretende elucidar si la Corte Suprema ha seguido sus propios precedentes (sentido interno) tanto como tribunal (dimensión institucional) como también cada uno de sus Ministros (dimensión personal). Con la última perspectiva, en cambio, se pretende esclarecer si el resto de los tribunales del país han seguido los precedentes establecidos por la Corte Suprema (sentido vertical).

Lo dicho hace evidente que lo primero que se debe dilucidar es si existe un seguimiento interno e institucional del precedente. En efecto, si no existe seguimiento de sus precedentes por parte de la propia Corte Suprema como órgano, no resulta posible evaluar el seguimiento interno y personal. Ahora bien, la existencia de un seguimiento interno e institucional de sus precedentes por ese Excelentísimo Tribunal al conocer del recurso de unificación de jurisprudencia ha sido confirmada por otras investigaciones 7 . Por tanto, resulta perfectamente posible evaluar el seguimiento interno y personal de tales precedentes.

Pues bien, esta investigación tiene precisamente como objetivo evaluar el seguimiento interno y personal de los precedentes establecidos por la Corte Suprema. En otras palabras, su finalidad es revisar si cada uno de los Ministros de la Corte Suprema aplicó el precedente establecido en una determinada materia de Derecho, en cada uno de los casos posteriores iguales a aquel. En tal sentido, es la continuación y complemento de una de las que analizó el

7. Sото (20I3), pp. 2i 5-250; Díaz et al (20I5), pp. I Iо5-I I I. 
seguimiento del precedente a nivel interno e institucional ${ }^{8}$. Ahora bien, este estudio se limita a los recursos de unificación de jurisprudencia deducidos en el cuadrienio que sigue a la incorporación del recurso de unificación de jurisprudencia laboral en el ordenamiento jurídico chileno, esto es, entre el 29 de marzo de 2008 y el 29 de marzo de 20 I 2. En lo concreto, esto se traduce en la revisión de sentencias pronunciadas entre los años 2008 y 2013.

De acuerdo con las precisiones que se han entregado, la pregunta que guía esta investigación puede ser formulada del siguiente modo: ¿Se ha producido un seguimiento de los precedentes establecidos por la Corte Suprema por parte de sus propios Ministros desde la incorporación del recurso de unificación de jurisprudencia laboral al ordenamiento jurídico chileno y hasta el 20I3? En otras palabras, ¿se resuelven de la misma manera los casos iguales? La hipótesis de este trabajo es que no existe una actitud precedencial en los Ministros de la Corte Suprema que han conocido de los recursos de unificación de jurisprudencia laboral en dicho período.

La importancia de esta investigación es, seguramente, mayor que el análisis del seguimiento interno e institucional. Esto se debe a que la vocación precedencial de un tribunal colegiado, y particularmente de la Corte Suprema, se manifiesta no tanto en el seguimiento institucional de sus propios precedentes. Esa vocación se evidencia con mayor nitidez al analizar el comportamiento de cada uno de los Ministros que deben resolver los casos futuros iguales a aquel en el que se fijó el precedente. En efecto, la permanencia del precedente adquiere solidez (a) si los Ministros que establecieron por primera vez esa interpretación la mantienen, (b) si los Ministros que no intervinieron en la decisión del caso que fijó dicha interpretación están dispuestos a seguirla con independencia de sus propias preferencias, y, (c) por sobre todo, si los Ministros que participaron de la decisión que generó el precedente y optaron por una interpretación diversa de la asumida por la mayoría, están dispuestos a abandonar su propia preferencia interpretativa y adoptar la establecida en el precedente.

Desde el punto de vista estructural, el discurso que sigue se vertebra en torno a cuatro apartados. En el primero de ellos se entrega un marco conceptual básico para la comprensión de lo expuesto en este trabajo. En el segundo se presenta la metodología seguida para realizar el análisis conducente a responder la pregunta que guía esta investigación. En el tercero se analizan los resultados alcanzados tras analizar cada una de las materias de Derecho resueltas

8. Se trata de Díaz et al (20I4). 
mediante el recurso de unificación de jurisprudencia. El trabajo culmina con las pertinentes conclusiones.

\section{Marco conceptual}

Según se ha expresado más arriba, la pregunta que guía la investigación es la siguiente: $¿$ Se ha producido un seguimiento de los precedentes establecidos por la Corte Suprema por parte de sus propios Ministros desde la incorporación del recurso de unificación de jurisprudencia laboral al ordenamiento jurídico chileno y hasta el 20I3? En otras palabras, se intenta esclarecer si la Corte Suprema ha resuelto de la misma manera los casos iguales. A partir de esta pregunta misma, resulta necesario precisar el sentido en que se utilizan aquí las expresiones "precedente», «seguimiento del precedente», «seguimiento del precedente por parte de los Ministros de la Corte Suprema», «caso» y «casos iguales».

a) El precedente es la razón normativa (o ratio decidendi) que sirve de fundamento directo a la decisión adoptada en un caso judicial anterior y que puede servir de fundamento jurídico para resolver un caso presente ${ }^{9}$. Normalmente constituye la interpretación de una norma legislada ${ }^{\mathrm{Io}}$, por lo que, parafraseando a Farber, limita la extensión de los significados que pueden ser incorporados al Derecho ${ }^{\text {II }}$. En el presente caso, se trata de la interpretación elegida por la Corte Suprema de Chile, de entre aquellas que compiten para atribuir significado a una determinada disposición del ámbito laboral.

b) El seguimiento del precedente, por su parte, consiste en «la obediencia al precedente» ${ }^{\mathrm{2}}$, es decir, en la aplicación de la ratio decidendi o razón normativa que sirve de fundamento a una decisión anterior, en los futuros casos iguales a aquel. Siguiendo a Schauer, consiste en que el tratamiento previo del caso $\mathrm{X}$ en la manera Y constituye, únicamente en razón de su linaje histórico,

9. Llewellyng (i989) p. I 5 .

Io. Con menor frecuencia se tratará de una interpretación que deriva del ordenamiento jurídico en su conjunto, con la finalidad de colmar una laguna jurídica.

I r. En realidad el autor expresa esta idea en relación con la Constitución de Estados Unidos, pero puede perfectamente ser aplicado al Derecho legislado en su conjunto. FARBER (2006) p. I 202.

I2. ReHNQUist (I986) p. 347. 
una razón para tratar $\mathrm{X}$ en la manera $\mathrm{Y}$ cuando $\mathrm{X}$ ocurra de nuevo ${ }^{\mathrm{I}}$. El apartamiento del precedente, por tanto, consiste en aplicar una razón normativa distinta de la establecida en el caso anterior a futuros casos iguales a aquel.

c) El seguimiento del precedente por parte de los Ministros de la Corte Suprema se produce en tres casos. Primero, si los Ministros que generaron el precedente lo aplican en los siguientes casos iguales a aquel en el cual se estableció. Segundo, si los Ministros que participaron del conocimiento del caso en el que se fijó el precedente y sostuvieron una interpretación disidente, están dispuestos a adoptar la posición establecida por la mayoría en los siguientes casos iguales al primero. Y tercero, si los Ministros que no concurrieron a la decisión del caso en que se fijó el precedente lo siguen, aplicándolo en los siguientes casos iguales a aquel.

Por el contrario, no existe seguimiento del precedente por parte de los $\mathrm{Mi}$ nistros de la Corte Suprema en las situaciones opuestas. Esto es, en primer lugar, si los Ministros que generaron el precedente aplican una razón normativa distinta en los casos siguientes iguales a aquel en que se estableció. En segundo lugar, si los Ministros que sustentaron el voto de minoría en un determinado caso (y por tanto una ratio decidendi diversa) lo mantienen en los siguientes casos iguales a aquel. Y, en tercer lugar, si los Ministros que no concurrieron a la decisión del caso en el que se fijó el precedente aplican interpretaciones diversas de este último.

En este punto conviene precisar que a lo largo del presente trabajo la expresión Ministro se utiliza de manera genérica para todos los que suscriben las sentencias analizadas, sea que lo hagan en calidad de Ministros propietarios ${ }^{\mathrm{I}}$, de Ministros suplentes ${ }^{15}$ o de abogados integrantes ${ }^{16}$.

I3. SChauer ( I987) p. 57 I.

I4. El artículo 244 del Código Orgánico de Tribunales dispone que es Ministro propietario «el que es nombrado para ocupar perpetuamente o por el período legal una plaza vacante».

I 5. De acuerdo con el artículo 244 del Código Orgánico de Tribunales, es Ministro suplente «el que es nombrado para que desempeñe una plaza que no ha vacado, pero que no puede ser servida por el propietario en razón de hallarse suspenso o impedido».

I6. Los abogados integrantes son profesionales designados por el Presidente de la República, previa propuesta en terna por la Corte Suprema, que reemplazan a los Ministros de la Corte Suprema o de las Cortes de Apelaciones que por inhabilidad o por falta dejan a la Corte o alguna de sus salas sin el número de jueces necesario para 
d) La expresión caso individual o caso concreto alude a la reconstrucción de un acontecimiento acaecido en un momento y en un lugar determinados a partir de sus elementos relevantes, así considerados desde la perspectiva de su evaluación jurídica ${ }^{17}$. Ahora bien, entre los casos individuales es posible distinguir casos actualmente sometidos a enjuiciamiento ${ }^{\mathrm{I}}$, casos judicialmente resueltos $^{19}, \mathrm{y}$ casos ficticios debidamente contextualizados ${ }^{20}$. Por cierto en este momento sólo interesan casos individuales judicialmente resueltos, esto es, casos concretos que fueron sometidos a conocimiento de los tribunales y que cuentan con una sentencia final, específicamente una sentencia de unificación de jurisprudencia.

e) Casos iguales son aquellos casos individuales o concretos que coinciden en la totalidad de sus propiedades relevantes. Ahora bien, para determinar si dos casos individuales coinciden en la totalidad de sus propiedades relevantes es necesario determinar si pueden ser subsumidos en un mismo caso genérico. El término caso genérico, por su parte, constituye la abstracción de acontecimientos reales construida a partir de ciertos elementos comunes cuya concurrencia permite distinguirlo de otros casos genéricos ${ }^{2 \mathrm{I}}$. Ahora bien, y siguiendo la nomenclatura utilizada por el Código del Trabajo, los casos individuales iguales son aquellos que presentan la misma materia de Derecho objeto del juicio ${ }^{22}$, esto es, que plantean el mismo problema jurídico a ser resuelto.

el conocimiento y resolución de las causas que les estuvieren sometidas. Ver artículos 2I 5, 2 I 7 y 2 I9 del Código Orgánico de Tribunales.

I7. Ver Alchourrón (2000) pp. I7 y i 8.

I8. Por ejemplo, el hecho judicial de carácter laboral por el que María reclama a Juan el pago de la remuneración correspondiente a los meses de enero, febrero y marzo del presente año.

I9. Por ejemplo, la contratación de reemplazantes resuelta en la sentencia pronunciada por la Corte Suprema en la causa rol 35I4-20I4.

20. Todo hecho ficticio que entregue información casuística, tales como identificación de intervinientes, lugar, día, hora y sucesos concretos, que permita presentarlo como único, puede considerarse un ejemplo de caso individual ficticio.

2i. Para Alchourrón (2000) p. I7, un caso genérico «es una mera descripción de ciertas propiedades de un conjunto de acontecimientos».

22. Artículo 483, inciso segundo, del Código del Trabajo. 


\section{Metodología}

Desde un punto de vista metodológico, se deben distinguir dos clases de procedimientos. De un lado, los seguidos para determinar el universo de recursos de unificación de jurisprudencia que serían objeto de análisis. De otro lado, los tendientes a evaluar el comportamiento precedencial de los Ministros de la Corte Suprema.

\section{Determinación de los recursos que son objeto de análisis}

Los procedimientos seguidos para determinar los recursos de unificación de jurisprudencia que en definitiva son objeto de la presente investigación fueron aplicados y explicados en otro estudio. A continuación se sintetizan los aspectos esenciales de tales procedimientos ${ }^{23}$.

El universo de casos que es objeto de la presente investigación está integrado por el conjunto de sentencias pronunciadas por la Corte Suprema sobre los recursos de unificación de jurisprudencia laboral deducidos entre el 29 de marzo de 2008 y el 29 de marzo de 2012 que presentan las siguientes características: (a) la sentencia acoge o rechaza el recurso ${ }^{24}$, (b) existe pronunciamiento sobre la materia de Derecho objeto del juicio ${ }^{25}$; y (c) existen dos o más sentencias sobre una misma materia de Derecho ${ }^{26}$.

23. DíAz et al (2014).

24. Al considerar únicamente los recursos que acogen o rechazan el recurso de unificación de jurisprudencia, se excluyen aquellas causas en que se declaró la deserción del recurso (artículos 200 y 20 I del Código de Procedimiento Civil, aplicable supletoriamente por disposición del artículo 432 del Código del Trabajo), se le tuvo por no presentado (artículo 3 I del Código de Procedimiento Civil, aplicable supletoriamente por disposición del artículo 432 del Código del Trabajo), fue declarado inadmisible por la Corte Suprema (artículo 483-A, inciso séptimo, del Código del Trabajo) o fue desistido por la parte que lo presentó (artículos I 48 y I 50 del Código de Procedimiento Civil, aplicable supletoriamente por disposición del artículo 432 del Código del Trabajo).

25. En un importante número de casos la Corte Suprema se pronunció rechazando el recurso, pero por razones vinculadas con la inadmisibilidad del mismo. Estos son los casos en los que no existe pronunciamiento sobre la materia de Derecho objeto del juicio.

26. La investigación permitió determinar que los recursos acogidos o rechazados en 
El universo delimitado del modo que acaba de explicarse está constituido por un total de I4I sentencias, las que fueron pronunciadas entre el i9 de noviembre de 2008 y el I I de abril de 20 I 3 pues, como puede suponerse, la Corte Suprema tardó algún tiempo en pronunciarse sobre ellos desde el momento en que se presentaron ante la misma. Estas I4I sentencias emiten pronunciamiento sobre 17 materias de Derecho. Por cierto respecto de cada una de estas materias de Derecho existen dos o más sentencias.

De este modo, la presente investigación analiza el comportamiento precedencial de los Ministros de la Corte Suprema en las 17 materias de Derecho que agrupan las mencionadas I4I sentencias.

\section{Evaluación del comportamiento precedencial de los Ministros de la Corte Suprema}

Para determinar el comportamiento precedencial de los Ministros de la Corte Suprema al pronunciarse sobre cada materia de Derecho incluida en las sentencias analizadas se utilizó el siguiente procedimiento, integrado por tres pasos fundamentales:

I) En primer lugar se identificaron los Ministros que suscribieron la primera sentencia pronunciada en cada una de las I7 materias de Derecho objeto del juicio. De este modo se determinó qué Ministros habían generado la ratio decidendi de dicha materia de Derecho y cuáles se habían opuesto a aquella. Esto hizo posible el análisis del comportamiento precedencial de los Ministros que debieron pronunciarse respecto de los siguientes casos relativos a la misma materia.

2) A continuación se identificó a los Ministros que suscribieron las sentencias posteriores a la primera, dentro de una misma materia de Derecho. Estos Ministros se dividieron en tres grupos:

a) Los que suscribieron la primera sentencia de cada materia de Derecho y sostuvieron la ratio decidendi fijada en la misma:

b) Los que suscribieron la primera sentencia de cada materia de Derecho y discreparon de la ratio decidendi fijada en la misma:

los que existía pronunciamiento sobre la materia de Derecho objeto del juicio se agrupaban en 45 universos temáticos. De ellos 28 contenían un solo recurso, por lo que fueron desechados. De este modo, sólo restan 17 universos temáticos con dos o más pronunciamientos recaídos en la respectiva materia de Derecho. 
c) Los que no suscribieron la primera sentencia de cada materia de Derecho, pero sí alguna de las posteriores.

3) Por último, se analizó el sentido en que se pronunciaron los Ministros en los casos posteriores al primero dentro de cada materia de Derecho. En el caso de aquellos incluidos en el grupo (a) para determinar si mantenían la ratio decidendi. En el caso de los que formaron el grupo (b), para saber si se sumaban a precedente establecido, abandonando sus preferencias personales. Y en el caso de los Ministros del grupo (c) para elucidar si adherían a la interpretación jurídica unánime o mayoritariamente sostenida.

\section{Resultados}

El comportamiento precedencial de los Ministros de la Corte Suprema en cada una de las I 7 materias de Derecho ${ }^{27}$ en que se pronunciaron dos o más decisiones fue el que se explica a continuación ${ }^{28}$.

I) Aplicación de las normas sobre indemnización por años de servicios e indemnización sustitutiva del aviso previo reguladas en el Código del Trabajo a profesionales de la educación contratados anualmente por varios períodos consecutivos.

En esta materia de Derecho se emitieron dos pronunciamientos por la Corte Suprema ${ }^{29}$. En ambos se estableció como ratio decidendi que el Código del Trabajo no resulta supletoriamente aplicable a los profesionales de la educación que prestan servicios para una municipalidad en calidad de contratados para efectos de entender que sus contratos a plazo se transforman en contratos de duración indefinida. Por tanto, no tienen derecho a la indemnización por años de servicios ni a la indemnización sustitutiva del aviso previo.

La primera sentencia fue adoptada por la unanimidad de los Ministros de la sala ${ }^{30}$. Lo mismo ocurrió en la segunda, en la que se mantuvieron tres de

27. La denominación de cada una de las I 7 materias de Derecho que a continuación se revisan sigue la denominación utilizada en Díaz et al (2014).

28. En algunas de las notas al pie que siguen se indican los nombres de Ministros. Cuando dicho nombre no va seguido de su calidad, se trata de un Ministro propietario.

29. Las dos causas son las siguientes: Corte Suprema, Orellana con Ilustre Municipalidad de El Monte, rol 7154-2010 y Corte Suprema, Tudela con Corporación Municipal de Servicio y Desarrollo de Maipú, rol 70-20 I I.

30. P. Valdés, G. Pérez, R. Egnem, R. Jacob, y P. Figueroa (abogado integrante). 
ellos $^{31}$, y los dos que se incorporaron se sumaron a la interpretación previamente sostenida ${ }^{32}$.

2) Procedencia de la sanción establecida en el artículo I62, inciso séptimo, cuando la existencia de la relación laboral ha sido establecida por sentencia judicial.

Sobre esta materia de Derecho la Corte Suprema se pronunció en nueve sentencias ${ }^{33}$. En todas ellas sostuvo como ratio decidendi que la sanción establecida en el artículo I62, inciso séptimo, del Código del Trabajo no es aplicable al empleador cuando la existencia de la relación laboral ha sido establecida por sentencia judicial.

La primera decisión fue acordada con el voto en contra del Ministro Sergio Muñoz ${ }^{34}$, quien estimó procedente la sanción en referencia aun cuando la existencia de la relación laboral fuera declarada por sentencia judicial. A este Ministro no le correspondió conocer el resto de las causas relativas a la misma materia de Derecho, de modo que no resulta posible evaluar su comportamiento precedencial. Por su parte, los i I Ministros que suscribieron las sentencias posteriores a la primera siguieron la interpretación establecida en aquella ${ }^{35}$.

3) Procedencia de la sanción establecida en el artículo I62, inciso séptimo,

3 I. Rosa Egnem S., Roberto Jacob Ch., y Patricio Figueroa S. (abogado integrante).

32. Rosa María Maggi D. y Jorge Lagos G. (abogado integrante).

33. Las nueve causas son las siguientes: Corte Suprema, Núñez con Sociedad Contractual Minera Tambillos, rol 852-20Io; Corte Suprema, Villanueva con Fisco de Chile Armada de Chile, rol 5447-2010; Corte Suprema, Araya con Bodega La Esperanza Viñedos Errázuriz Ovalle S.A., rol ror 20-201о; Corte Suprema, Soza con Televisión Nacional de Chile, rol 205-20I I; Corte Suprema, Acosta y Otros con Sociedad Depetris Deflorian Hnos. Ltda., rol I I6-20I I; Corte Suprema, Araya con Monte Nevado Ingeniería y Otros, rol 9375-20I0; Corte Suprema, Orrego con Empresa Periodística La Cuarta S.A., rol 8989-20I I; Corte Suprema, Olivares con Pontificia Universidad Católica de Chile, rol I 855-20I2; y Corte Suprema, Riquelme con Pontificia Universidad Católica de Chile Corporación de Televisión, rol I68I-20I 2.

34. Urbano Marín V., Sergio Muñoz G., Patricio Valdés A., Gabriela Pérez P., y Rosa María Maggi D.

35. Rosa Egnem S., Roberto Jacob Ch., Guillermo Silva G., Arturo Prado P., Juan Escobar Z. (Ministro suplente).Rafael Gómez B. (abogado integrante), Ricardo Peralta V. (abogado integrante), Patricio Figueroa S. (abogado integrante), Jorge Lagos G. (abogado integrante), Alfredo Prieto B. (abogado integrante) y Virginia Halpern M. (abogado integrante). 
cuando la diferencia entre la remuneración pagada y la devengada favorece al trabajador y esto ha sido establecido por sentencia judicial.

La Corte Suprema se ha pronunciado en seis oportunidades sobre esta materia de Derecho ${ }^{36}$, que por cierto es muy similar a la anterior. En los seis casos sostuvo como ratio decidendi que la sanción establecida en el inciso séptimo del artículo r 62 del Código del Trabajo no resulta aplicable en aquellos casos en los que la diferencia entre la remuneración pagada y la que se debía pagar favorece al trabajador y esta última ha sido determinada por resolución judicial.

La primera decisión recaída en esta materia de Derecho fue adoptada por tres votos contra dos. La posición de minoría, que entendía aplicable la sanción del artículo I62, fue suscrita por los abogados integrantes Benito Mauriz y Patricio Figueroa S. Estos abogados no volvieron a resolver esta materia de Derecho, de modo que no es posible evaluar su comportamiento precedencial. Por su parte, los io Ministros que suscribieron las sentencias posteriores a la primera siguieron la interpretación establecida en aquella por la mayoría ${ }^{37}$.

4) Procedencia del beneficio establecido en el inciso primero del artículo 45 (semana corrida) a los trabajadores con remuneración mixta cuya parte variable no se devenga día a día.

El máximo tribunal se ha pronunciado en veinte oportunidades respecto de esta materia de Derecho ${ }^{38}$. Al respecto ha establecido como razón para la

36. Las seis causas son las siguientes: Corte Suprema, Saldaña con Interagro Comercio y Ganado S.A., rol 9265-2009; Corte Suprema, Pereira con Consorcio RDTC S.A., rol 545 I-20Io; Corte Suprema, Abello con Librería Giorgio Temuco y CIA Limitada, rol i39i-20I i; Corte Suprema, Boasso con Rosa, rol 4584-20I i; Corte Suprema, Dussuel con Colegio San Bartolomé De Nos S.A., rol 5964-20 I ; y Corte Suprema, Véliz con TP Chile S.A., rol 820-20I2.

37. Rosa María Maggi D., Roberto Jacob Ch., Rosa Egnem S., Juan Fuentes B., Guillermo Silva G., Juan Escobar Z., Ministro suplente, Alfredo Pfeiffer R., Ministro suplente, Ricardo Peralta V., abogado integrante, Patricio Figueroa S., abogado integrante, Juan Fuentes B., Rafael Gómez B., abogado integrante.

38. Las veinte causas son las siguientes: Corte Suprema, A.F.P. Provida con Román, rol 475 I-2010; Corte Suprema, Gómez con ING AFP Capital S.A., rol 6019-2010; Corte Suprema, Prado con ING AFP Capital S.A., rol 6552- 20Io; Corte Suprema, Reyes con A.F.P. Próvida S.A., rol 610I- 2010; Corte Suprema, Cabrera con A.F.P. Próvida S.A., rol 6r I4-20го; Corte Suprema, Pereira con A.F.P. Próvida S.A., rol 6I I 5-20Io; Corte Suprema, Cáceres con ING AFP Capital S.A., rol 6777-20Io; Corte Suprema, Monroy y otra con AFP Hábitat S.A., rol 6450-20Io; Corte Suprema, 
decisión que los trabajadores que cuentan con remuneración mixta, integrado por sueldo mensual y remuneraciones variables, sólo tienen derecho al pago de la semana corrida en la medida que sus remuneraciones variables sean devengadas día a día.

Las tres primeras sentencias dictadas en esta materia de Derecho son del mismo día ${ }^{39}$, y fueron adoptadas por cuatro votos contra uno, este último sostenido por el Ministro Roberto Jacob ${ }^{40}$. Este Ministro sólo intervino en una de las otras causas en las que se vio esta misma materia de Derecho, en la que mantuvo su disidencia ${ }^{4 \mathrm{I}}$. El otro Ministro que sostuvo un voto disidente fue Jaime Rodríguez, en una sentencia pronunciada casi dos meses después de decidirse los tres primeros casos relativos a esta materia de Derecho ${ }^{42}$. Por su parte, los otros Io Ministros que suscribieron las sentencias posteriores a la primera siguieron la interpretación establecida en aquella por la mayoría ${ }^{43}$.

Rencoret y Otro con AFP Provida S.A., rol 7208-2010; Corte Suprema, Caro y Otros con AFP Provida S.A., rol 6932-20Io; Corte Suprema, Sindicato de Trabajadores de la AFP Provida S.A. con AFP Provida S.A., rol III7-20I ; Corte Suprema, Valenzuela con AFP Capital S.A., rol 8860-2010; Corte Suprema, Osses y Otros con AFP Habitat S.A., rol 470-20I I; Corte Suprema, Alarcón con Administradora de Fondos de Pensiones Capital S.A. rol I 863-20I I; Corte Suprema, Sindicato Unificado de Trabajadores de Isapre Banmédica S.A. con Isapre Banmédica S.A., rol 2739-20I I; Corte Suprema, Aravena y Otros con VTR Global Com S.A., rol 8788-20I I; Corte Suprema, Gonzáles y Otros con AFP Provida S.A., rol 8322-20I I; Corte Suprema, Parada con AFP Capital S.A., rol I07I3-20I I; Corte Suprema, Kerbernhard con Recaudación y Cobranzas S.A., rol 9579-20I I; y Corte Suprema, Irazzoky con Comercial Rey S.A., rol i i 873-20II.

39. Se trata de las causas Corte Suprema, A.F.P. Provida con Román, rol 475 I2010; Corte Suprema, Gómez con ING AFP Capital S.A., rol 6019-2010; Corte Suprema, Prado con ING AFP Capital S.A., rol 6552- 2010, todas las cuales son del 27 de enero de 20 I.

40. Patricio Valdés A., Gabriela Pérez P., Rosa Egnem S., Roberto Jacob Ch., y Rafael Gómez B., abogado integrante.

4I. Corte Suprema, Alarcón con Administradora de Fondos de Pensiones Capital S.A. rol I 863-20I I.

42. Corte Suprema, Monroy y otra con AFP Hábitat S.A., rol 6450-2010, cuya sentencia es de 3 I de marzo de 20 I .

43. Rosa María Maggi D., Jorge Medina C., María Eugenia Sandoval, Juan Fuentes B., Alfredo Pfeiffer R., Ministro suplente, Patricio Figueroa S., abogado integrante, 
5) Inclusión de asignaciones que no constituyen remuneración en el concepto última remuneración mensual del artículo I 72 del Código del Trabajo.

La Corte Suprema se ha pronunciado en dieciséis oportunidades sobre esta materia de Derecho ${ }^{44}$. En todas las sentencias recaídas sobre el punto ha sostenido que la expresión última remuneración mensual del artículo I72 del Código del Trabajo sólo incluye aquellas prestaciones que tienen carácter de remuneración conforme al artículo 4I del mismo Código. En consecuencia, no se incluyen en el concepto «última remuneración mensual» la colación, la movilización, los viáticos y otros que no tienen carácter de remuneración.

La primera sentencia dictada en esta materia de Derecho fue adoptada por tres votos contra dos, posición de minoría que fue sostenida por las Ministras Rosa Egnem y Rosa María Maggi ${ }^{45}$. Las Ministras mantuvieron su disidencia en todas las demás causas en las que les correspondió intervenir, lo que ocurrió con una o con ambas en I 4 de las I 5 causas siguientes en las que se vio la misma materia de Derecho. A esta posición de minoría sólo se sumó el Ministro Pedro Pierry, en una causa cuya sentencia se pronunció 8 meses después de la primera $^{46}$. Por su parte, los otros ro Ministros que suscribieron las sentencias

Rafael Gómez B., abogado integrante, Ricardo Peralta V., abogado integrante, Virginia Cecily Halpern M., abogado integrante, Arturo Prado P., abogado integrante.

44. Las dieciséis causas son las siguientes: Corte Suprema, Vega con Análisis y Servicios S.A., rol 9603-2009; Corte Suprema, Alegría con Laboratorio Koni Cofarm S.A., rol 4196-20ıо; Corte Suprema, Alarcón con Análisis y Servicios S.A, rol 6074-2010; Corte Suprema, Flores y otro con Servicios Prosegur Limitada rol 588I-20Io; Corte Suprema, Zúñiga con Transportes Aéreos del Mercosur S.A., rol 7362-2010; Corte Suprema, Fernández con Inesa Chile S.A. rol 8I 55-2010; Corte Suprema, Monsalve con Sociedad Educacional ArabPerezLtda rol 3169-20 I ; Corte Suprema, Berrios con Pullman cargo rol 3 I68-20 I ; Corte Suprema, Rodríguez con Inversiones Alsacia S.A, rol 4735-20I I; Corte Suprema, Gallardo con Red Capacita S.A., rol 5843-20I I; Corte Suprema, Campusano con AFP Planvital S.A,, rol 8504-20I i; Corte Suprema, Caro con Envases Del Pacífico S.A., rol 9242-20I I; Corte Suprema, Azócar con Sociedad Comercial Wingel Ltda., rol 9838-20I I; Corte Suprema, Becker con Premium Nutregg S.A., rol 36I-20I 2; Corte Suprema, Loyola con Compass Catering S.A., rol 208-2012; y Corte Suprema, Ponce con Distribuidora de Industrias Nacionales S.A DIN, rol II655-20II.

45. Corte Suprema, Vega con Análisis y Servicios S.A., rol 9603-2009

46. Corte Suprema, Rodríguez con Inversiones Alsacia S.A, rol 4735-20 I I. 
posteriores a la primera siguieron la interpretación establecida en aquella por la mayoría ${ }^{47}$.

6) Procedencia de la indemnización por años de servicios establecida en el artículo $2^{\circ}$ transitorio de la ley 19.070 , respecto de profesionales de la educación que renunciaron voluntariamente ajustándose a las exigencias del artículo $2^{\circ}$ transitorio de la ley 20.1 58 .

La Corte Suprema cuenta con cincuenta y un sentencias relativas a esta materia de Derecho ${ }^{4}$. En todas ellas ha sostenido que no resulta procedente el

47. Roberto Jacob Ch., Alfredo Pfeiffer R., Ministro suplente, Juan Escobar Z, Ministro suplente, Ricardo Peralta V., abogado integrante, Patricio Figueroa S., abogado integrante, Rafael Gómez B., abogado integrante, Jorge Lagos G., abogado integrante, Virginia Cecily Halpern M., Abogado integrante, Arnaldo Gorziglia B., abogado integrante, Jorge Baraona G., abogado integrante.

48. Las cincuenta y un causas son las siguientes: Corte Suprema, Mejías con Municipalidad de Valdivia, rol 8809-2009; Corte Suprema, Peralta con Municipalidad de Chiguayante, rol 9024-2009; Corte Suprema, Núñez Sonia y Otros con Ilustre Municipalidad de Lanco, rol 627-2010; Corte Suprema, Alarcón con Municipalidad de San Pedro de la Paz, rol 2 I2-20Iо; Corte Suprema, Ayala con Corporación Municipal de Desarrollo Social de Iquique, rol 7930-2009; Corte Suprema, Cea y Otros con I. Municipalidad de Coronel, rol I I67-20Io; Corte Suprema, Machuca con Ilustre Municipalidad de San Pedro de la Paz, rol I7I-20Iо; Corte Suprema, Ramírez con Ilustre Municipalidad de Hualpén, rol 91 5-2010; Corte Suprema, Candia con I. Municipalidad de Yumbel, rol I346-20Iо; Corte Suprema, Castro y Otros con Municipalidad de Colbún, rol I98420Iо; Corte Suprema, Espinosa con I. Municipalidad de Linares, rol 3357-2010; Corte Suprema, González con Ilustre Municipalidad de los Ángeles, rol 2975-2010; Corte Suprema, Sepúlveda con Ilustre Municipalidad de Talcahuano, rol I3 I2-20Io; Corte Suprema, Uribe y Otro con I. Municipalidad de Paillaco, rol I985-2010; Corte Suprema, Bustamante y Otro con I. Municipalidad de Parral, rol I 584-2010; Corte Suprema, Pérez y Otros con I. Municipalidad de Mariquina, rol 24 I9-2010; Corte Suprema, Avendaño y Otros con Ilustre Municipalidad de Curepto, rol I349-20Io; Corte Suprema, Ávila y Otros con Ilustre Municipalidad de Parral, rol I954-20Io; Corte Suprema, Encina y Otros contra I. Municipalidad de Yerbas, rol I 586-20Io; Corte Suprema, Alejandrina con Ilustre Municipalidad de Talca, rol I392-20I0; Corte Suprema, Corvalán con Ilustre Municipalidad de Talca, rol I345-20I0; Corte Suprema, Libis con Municipalidad de Valdivia, rol I639-2010; Corte Suprema, Lienlaf Marilaf y Otras con I. Municipalidad de Mariquina, rol 629-2010; Corte Suprema, Medel con Ilustre Municipalidad de Talca, rol I489-20Io; Corte Suprema, Rivera con Ilustre Municipalidad de Talca, rol I49I-20Io; Corte Suprema, San Martín con Ilustre Municipalidad 
pago de la indemnización por años de servicios del artículo segundo transitorio de la Ley I9.070, si el docente voluntariamente ha renunciado para obtener la bonificación prevista en el artículo segundo transitorio de la Ley 20.I 58 .

Todas las sentencias recaídas en esta materia de Derecho fueron adoptadas por la unanimidad de los Ministros que la suscribieron. Sólo se exceptúa parcialmente el Ministro Jacob, quien en la segunda de las seis causas en que intervino suscribe sin reparo la sentencia de unificación de jurisprudencia, pero en la sentencia de reemplazo sostiene que no procede invalidar la resolución de la Corte de Apelaciones porque, pese a discrepar de la interpretación sostenida sobre la materia de Derecho de que trata esta causa, no contiene vicio alguno ${ }^{49}$.

de Talcahuano, rol 2454-2010; Corte Suprema, Agurto y Otros con Ilustre Municipalidad de Canquenes, rol 3352-2010; Corte Suprema, Inocencio con I. Municipalidad de Quillota, rol 3609-2010; Corte Suprema, Arancibia y Otros con Ilustre Municipalidad de Quillota, rol 3488-2010; Corte Suprema, Moya con Ilustre Municipalidad de Linares, rol 371 8-2010; Corte Suprema, Muena y Otros con Municipalidad de Linares, rol I959-20I0; Corte Suprema, Concha con Ilustre Municipalidad de Constitución, rol 2578-2010; Corte Suprema, Silva con Municipalidad de Huechuraba, rol 3991-2010; Corte Suprema, Herrera con Corporación de Desarrollo Social, rol 3846-2010; Corte Suprema, Aguilera con I. Municipalidad de Curicó, rol 3358-2010; Corte Suprema, Corvera con Ilustre Municipalidad de El Bosque, rol 3292-2010; Corte Suprema, Corvera con Ilustre Municipalidad de El Bosque, rol 3293-2010; Corte Suprema, Neira con I. Municipalidad de Hualqui, rol 3013-2010; Corte Suprema, Lorca y Otros con Ilustre Municipalidad de Arauco, rol 5062-2010; Corte Suprema, Constant y Otros con Ilustre Municipalidad de Lebu, rol 5010-2010; Corte Suprema, Araneda y Otros con Ilustre Municipalidad de los Álamos, rol 5833-2010; Corte Suprema, Fuentez y Otros con Ilustre Municipalidad de Lebu, rol 50 I I-20I0; Corte Suprema, Bravo con Corporación de Desarrollo I. Municipalidad de la Reina, rol 49 I I-20ıо; Corte Suprema, Silva con Corporación de Desarrollo Social de Providencia, rol 5835-2010; Corte Suprema, Meza y Otros con Municipalidad de Hualañé, rol 6763-20ıо; Corte Suprema, Cárcamo con Ilustre Municipalidad de Puerto Montt, rol 5132-20Io; Corte Suprema, Canales y otros con I. Municipalidad de San Rosendo, rol 437 I-2010; Corte Suprema, Abumada [esta es la carátula que aparece en la página web del Poder Judicial], rol 7828-20ıо; Corte Suprema, Mora con Municipalidad de Chiguayante, rol 6973-20I0; Corte Suprema, Córdova con Ilustre Municipalidad de Curicó, rol 8859-20Io; y Corte Suprema, Cárdenas con Corporación Municipal de La Florida, rol ıо066-20 I .

49. Esta disidencia parcial se expresa en la causa Corte Suprema, Fuentez y Otros con Ilustre Municipalidad de Lebu, rol 50 I I-2010. 
Por su parte, los otros I4 Ministros que suscribieron las sentencias posteriores a la primera siguieron la interpretación establecida en aquella por la mayoría ${ }^{50}$.

7) Aplicación del Código del Trabajo a los contratos a honorarios suscritos entre un particular y una municipalidad bajo la ley s 8.883 .

La Corte Suprema cuenta con dos sentencias sobre esta materia de Derecho $^{5 \mathrm{I}}$. En ambas sostuvo que el Código del Trabajo no resulta aplicable a aquellas relaciones por las que una persona presta servicios personales para una municipalidad de conformidad con la ley I 8.883 , aun cuando se cumplan todos los elementos configuradores de un contrato de trabajo.

Las dos sentencias recaídas en esta materia de Derecho fueron adoptadas por la unanimidad de los Ministros que la suscribieron. Los dos Ministros que no concurrieron a la primera de ellas, pero sí a la segunda, se sumaron a la interpretación adoptada ${ }^{52}$.

8) Aplicación del Código del Trabajo a los contratos a honorarios suscritos entre un particular y la Administración del Estado bajo la ley i 8.834.

La Corte Suprema se ha pronunciado en cuatro oportunidades respecto de esta materia de Derechos ${ }^{53}$. En todas sostuvo que el Código del Trabajo no resulta aplicable a aquellas relaciones por las que una persona presta servicios personales para una municipalidad de conformidad con la ley r8.834, aun cuando se cumplan todos los elementos configuradores de un contrato de trabajo.

Las cuatro sentencias recaídas en esta materia de Derecho fueron adoptadas

50. Rosa María Maggi D., Rosa Egnem S., Roberto Jacob Ch., Sonia Araneda B.; Haroldo Brito C.; Margarita Herreros M.; Carlos Künsemüller L.; María Eugenia Sandoval, Benito Mauriz A., abogdo integrante; Luis Bates H., abogdo integrante; Ricardo Peralta V., abogado integrante, Rafael Gómez B., abogado integrante, Jorge Lagos G., abogado integrante, Virginia Cecily Halpern M., Abogado integrante.

5 I. Las dos causas son las siguientes: Corte Suprema, Lazo con Ilustre Municipalidad de Coquimbo, rol 6335-2009, y Corte Suprema, Torres con Ilustre Municipalidad de Coquimbo, rol 678I-2009.

52. Se trata de los abogados integrantes Nelson Pozo S. y Jorge medina C..

53. Las cuatro causas son las siguientes: Corte Suprema, Suazo con Fisco De Chile, Ministerio Secretaría General De Gobierno, rol 5839-20 I ; Corte Suprema, Contreras con Fondo De Solidaridad e Inversión Social, rol 8I I 8-20 I ; Corte Suprema, Hidalgo con Corporación De Fomento De La Producción, rol 5544-20Ir; y Corte Suprema, Espinoza con Fisco de Chile, Ministerio Secretaría General de la República, rol 462-2012). 
por la unanimidad de los Ministros que la suscribieron. Los 6 Ministros que no concurrieron a la primera de ellas se sumaron a la interpretación adoptada en la misma ${ }^{54}$.

9) Procedencia de la sanción establecida en el artículo I62, inciso séptimo, en caso de despido indirecto (o autodespido).

La Corte Suprema se ha pronunciado en cinco oportunidades respecto de esta materia de Derecho ${ }^{55}$. En todas ellas ha fijado como ratio decidendi que la sanción por nulidad del despido a que se refiere el inciso séptimo del artículo I 62 del Código del Trabajo no procede en el caso del autodespido contemplado en el artículo r7 I del mismo Código.

Las cinco sentencias recaídas en esta materia de Derecho fueron adoptadas por la unanimidad de los Ministros que la suscribieron. Los 7 Ministros que suscribieron las posteriores a la primera mantuvieron la interpretación sostenida en aquella ${ }^{56}$.

Io) Alcance de la responsabilidad de la empresa principal respecto de las remuneraciones y demás prestaciones devengadas por la empresa contratista a sus trabajadores entre el término del contrato de trabajo y su convalidación.

La Corte Suprema se ha pronunciado sobre esta materia de Derecho en tres oportunidades ${ }^{57}$. Este es el único caso en el que se produce una modificación en la ratio decidendi. En efecto, en la primera de ellas sostuvo que la empresa principal es responsable (solidaria o subsidiariamente) de las remuneraciones y demás prestaciones devengadas con posterioridad al término de la relación

54. Juan Escobar Z., Ministro suplente; Alfredo Pfeiffer R., Ministro suplente; Ricardo Peralta V., abogado integrante; Arturo Prado P., abogado integrante; Alfredo Prieto B., abogado integrante; y Virginia Cecily Halpern M., Abogado integrante.

55. Las cinco causas son las siguientes: Corte Suprema, Valdés con Administradora de Mutuos Hipotecarios del Centro S.A., rol 65 I0-201o; Corte Suprema, Yáñez con Cúneo, rol 704-20 I i; Corte Suprema, Ramírez Y Otros con Liceo Comercial Gabriela Mistral, rol 8488-20I I; Corte Suprema, Peralta con Corporación Municipal De Edu. Salud y Atenc. De Menores De Puente Alto, rol ro266-20 I ; y Corte Suprema, Marambio con Liceo Comercial Gabriela Mistral, rol 8892-20I I.

56. Pedro Pierry A; Guillermo Silva G; Juan Fuentes B; Juan Escobar Z., Ministro suplente; Ricardo Peralta V., abogado integrante; Virginia Cecily Halpern M., abogado integrante; y Arturo Prado P., abogado integrante.

57. Las tres causas son las siguientes: Corte Suprema, Solís con Diseño Paisajista, rol 7502-2010; Corte Suprema, Munizaga con Factor Seguridad Limitada, rol 966920I I; y Corte Suprema, Castillo con Bahamonde y Cia Ltda., rol 2500-20I 2. 
laboral por la empresa contratista a favor de sus trabajadores. En las dos siguientes estableció que la empresa principal no tenía tal responsabilidad.

Las tres sentencias recaídas en esta materia de Derecho fueron adoptadas por la unanimidad de los Ministros que la suscribieron. Los 4 Ministros que dictaron las posteriores a la primera mantuvieron la interpretación sostenida en aquella ${ }^{58}$.

I I) Interpretación de los incisos primero y segundo del artículo 5 Io, en lo relativo al cómputo de los plazos de prescripción extintiva en materia laboral.

La Corte Suprema se ha pronunciado en cuatro oportunidades respecto de esta materia de Derecho ${ }^{59}$. En todas ellas ha sostenido que el inciso primero del artículo 5 Io se refiere a los plazos de prescripción de acciones y derechos aplicables en caso que el contrato esté vigente, mientras que el inciso segundo regula dichos plazos en caso que el contrato de trabajo haya concluido.

Se trata de una materia de Derecho especialmente controvertida, pues en tres de las cuatro sentencias existieron dos Ministros disidentes y en el cuarto un Ministro disidente. En este sentido cabe destacar que los disidentes en la primera de las sentencias pronunciadas en la materia mantuvieron sus interpretaciones en los casos posteriores ${ }^{60}$. De los cuatro Ministros que se pronunciaron con posterioridad sobre el problema, tres de ellos se plegaron a la interpretación fijada por la Corte Suprema ${ }^{61}$, mientras el cuarto suscribió la postura disidente.

I2) Procedencia de la indemnización por lucro cesante, ante un despido injustificado, de conformidad con las normas del Código Civil en el proceso laboral.

La Corte Suprema ha emitido dos sentencias relativas a esta materia de De-

58. Guillermo Silva G; Virginia Cecily Halpern M., abogado integrante; Arturo Prado P., abogado integrante; y Emilio Pfeffer., abogado integrante.

59. Las cuatro causas son las siguientes: Corte Suprema, Burgos y Otros con I. Municipalidad de Lota, rol 45 Io-20ıо; Corte Suprema, Camaño y Otros con I. Municipalidad de Tomé, rol 6455-2010; Corte Suprema, Morecchio con I. Municipalidad de Tomé, rol 6936-2010; y Corte Suprema, Villagrán con Comercial Llanadas S.A., rol 7104-2010.

60. Se trata de la Ministra Rosa Egnem S. y del Ministro Roberto Jacob Ch.

6r. Rosa María Maggi D.; Ricardo Peralta V., abogado integrante; y Rafael Gómez B., abogado integrante. 
recho $^{62}$. En ambas ha sostenido que resulta procedente demandar lucro cesante en el ámbito laboral, debiendo aplicarse al efecto las normas del Código Civil que regulan esta clase de daño patrimonial en virtud del carácter supletorio que tiene dicho Código.

Las dos sentencias recaídas en esta materia de Derecho fueron adoptadas por la unanimidad de los Ministros que la suscribieron. Los 2 Ministros que concurrieron a la segunda de ellas mantuvieron la interpretación sostenida en la primera $^{63}$.

I3) Alcance de la expresión «incremento del valor hora, en los años en que procedió», para el cálculo del valor hora en el bono extraordinario anual (bono SAE).

La Corte Suprema se ha pronunciado en seis oportunidades respecto de esta materia de Derecho ${ }^{64}$. Al respecto se debe tener presente que para calcular el valor del bono extraordinario (bono SAE) que debe recibir cada profesor en los meses de diciembre de 2007 a 2010 , se deben considerar lo percibido por los sostenedores de establecimientos educacionales e esos mismos años en virtud de lo dispuesto en los artículos $6^{\circ}, 7^{\circ}$ y $8^{\circ}$ de la ley 19.933, a lo que se debe restar lo pagado por concepto de incremento del valor hora en ese mismo período, en los años que procedió (artículo $9^{\circ}$, inciso tercero, de la ley I9.933). Pues bien, la Corte Suprema en las seis decisiones recaídas en esta materia de Derecho sostuvo que la expresión «en los años que procedió» se refiere a los aumentos que ha experimentado el valor hora cronológica desde el año I998 en adelante, en virtud de la ley I9.598, de I999, y no sólo a los experimentados por el valor hora desde la dictación de la ley 20.1 58 , de 2006.

62. Las dos causas son las siguientes: Corte Suprema, Medina con Sistemas Internacionales de Calidad Ltda. y Otro, rol 8279-20ıо; y Corte Suprema, Campos y Otros con Empresa de Montajes Industriales Salfa S.A., rol 4259-20I I.

63. Sergio Muñoz G.; y Juan Fuentes B.

64. Los seis casos son los siguientes: Corte Suprema, Domke con Ilustre Municipalidad de Puerto Montt, rol I087I-20I I; Corte Suprema, Bravo y Otros con Ilustre Municipalidad de Osorno, rol 8035-20I I; Corte Suprema, Parra y Otros con Ilustre Municipalidad de Temuco, rol 787I-20I I; Corte Suprema, Aguirre con Corporación Municipal de Desarrollo Social de Antofagasta, rol 589-20I 2; Corte Suprema, Pereira con Ilustre Municipalidad de San Esteban, rol 2658-20 I2; y Corte Suprema, Poblete y Otros con Corporación de Desarrollo de la comuna de San Vicente de Tagua Tagua, rol 2506-20I2. 
Las seis sentencias recaídas en esta materia de Derecho fueron adoptadas por la unanimidad de los Ministros que la suscribieron. Los 6 Ministros que concurrieron a las posteriores a la primera mantuvieron la interpretación sostenida en esta última ${ }^{65}$.

I4) Aplicabilidad de la fórmula de cálculo del bono extraordinario anual (bono SAE) a los docentes del sector municipal.

La Corte Suprema ha emitido cuatro sentencias relativas a esta materia de Derecho ${ }^{66}$. En todas ha declarado que resulta aplicable a los profesionales de la educación del sector municipal la fórmula de cálculo del bono extraordinario anual (bono SAE) establecida en el artículo $9^{\circ}$, inciso tercero, de la ley I 9.933.

Las cuatro sentencias recaídas en esta materia de Derecho fueron adoptadas por la unanimidad de los Ministros que la suscribieron. Los 9 Ministros que concurrieron a la segunda y siguientes mantuvieron la interpretación sostenida en la primera ${ }^{67}$.

I 5) Aplicabilidad del procedimiento de Tutela de Derechos a funcionarios públicos «a contrata».

La Corte Suprema ha emitido tres sentencias relativas a esta materia de Derecho ${ }^{68}$. En todas ellas ha sostenido que el procedimiento de Tutela de Derechos contemplado en el libro V del Código del Trabajo no es aplicable a los funcionarios públicos a contrata. En consecuencia, los juzgados con jurisdicción laboral son absolutamente incompetentes para conocer de dicha materia.

Las tres sentencias recaídas en esta materia de Derecho fueron adoptadas

65. Carlos Künsemüller L.; Rosa Egnem S.; Juan Fuentes B.; Jorge Baraona G., abogado integrante; Virginia Cecily Halpern M., abogado integrante; y Jorge Lagos G., abogado integrante.

66. Las cuatro causas son las siguientes: Corte Suprema, Parra y Otros con Ilustre Municipalidad de Temuco, rol 787I-20I I; Corte Suprema, Cutiño con Ilustre Municipalidad de Puerto Aysén, rol 8780-20I I; Corte Suprema, Moya con Ilustre Municipalidad de Frutillar, rol I225 I-20I I; y Corte Suprema, Contreras con Ilustre Municipalidad de Puerto Montt, rol 2 I 54-20I 2.

67. Pedro Pierry A.; Sonia Araneda B.; Juan Escobar Z., suplente; Dinorah Cameratti R., suplente; Alfredo Pfeiffer R., suplente; Alfredo Prieto B., abogado integrante; Arturo Prado P., abogado integrante; Guillermo Piedrabuena R., abogado integrante; y Virginia Cecily Halpern M., abogado integrante.

68. Los tres casos son los siguientes: Corte Suprema, Vallejos y Otro con Fisco de Chile, rol 8680-20I I; Corte Suprema, Castillo con Intendencia Regional de la Araucanía, rol I972-20I I; y Corte Suprema, Gasca con Zuñiga, rol I 27 I 2-20I I. 
por la unanimidad de los Ministros que la suscribieron. Los seis Ministros que concurrieron a la segunda y siguientes mantuvieron la interpretación sostenida en la primera ${ }^{69}$.

I6) Aplicación de la ficción legal del artículo i 68 inciso cuarto del Código del Trabajo, para los efectos de la procedencia de la indemnización adicional que establece el artículo 87 del Estatuto Docente.

La Corte Suprema ha emitido tres sentencias en relación con esta materia de Derecho $^{70}$. En todas ellas ha declarado que la indemnización adicional a que se refiere el artículo 87 de la ley I9.070 no procede respecto de profesionales de la educación cuyo contrato ha concluido por una causal que el empleador no ha podido acreditar y, como consecuencia de ello, se aplica la ficción del artículo I 68 del Código del Trabajo en virtud de la cual se entiende que ha terminado por necesidades de la empresa.

Las tres sentencias recaídas en esta materia de Derecho fueron adoptadas por la unanimidad de los Ministros que la suscribieron. Los seis Ministros que concurrieron a la segunda y siguientes mantuvieron la interpretación sostenida en la primera ${ }^{7 \mathrm{I}}$.

I7) Poder liberatorio del finiquito válidamente celebrado.

La Corte Suprema ha dictado dos sentencias en relación con esta materia de Derecho ${ }^{72}$. «En ambos ha sostenido que el finiquito válidamente celebrado entre empleador y trabajador tiene pleno poder liberatorio en todo aquello que es objeto de dicho instrumento, sin que pueda obstar a esta conclusión la posible aplicación del principio de la realidad porque el trabajador luego de suscribir dicho finiquito continuó prestando los mismos servicios para el mismo empleador ${ }^{73}$.

69. G. Pérez P.; R. Egnem S.; A. Pfeiffer R., suplente; D. Cameratti R., suplente; R. Peralta V., abogado integrante; y A. Prado P., abogado integrante.

70. Las tres causas son las siguientes: Corte Suprema, Cabello con Cáceres, rol 3488-20 I i; Corte Suprema, Soto con Colegio Misionero de Agostini, rol I I 875-20 I I; y Corte Suprema, Castillo con Jara rol I I70-20I2.

7I. Alfredo Pfeiffer R.; Ricardo Peralta V., abogado integrante; Virginia Cecily Halpern M., abogado integrante; y Arturo Prado P., abogado integrante.

72. Las dos causas son las siguientes: Corte Suprema, Fuentealba Candia Lorena con I. Municipalidad San José, rol 5816-2009; y Corte Suprema, Salgado con Toledo $y$ otros, rol 83 I6-20Io.

73. Díaz (20I4) p. I I 2 I. 
En las dos sentencias recaídas en esta materia de Derecho la sentencia fue adoptada por la unanimidad de los Ministros. El único ministro que no suscribió la primera de ellas, pero sí la segunda, siguió la decisión previamente sostenida ${ }^{74}$.

\section{Conclusiones}

Los resultados que arroja la presente investigación permiten concluir, en esencia, lo siguiente:

I. Los Ministros que han pronunciado la sentencia en la que se establece el precedente mantienen su propia interpretación en todos los casos futuros iguales a aquel en el que se generó dicho precedente. Esto ocurre no sólo con los que establecieron de manera unánime o mayoritaria la ratio decidendi del respectivo caso, sino también con aquellos que sostuvieron la disidencia.

Lo anterior evidencia que los Ministros que sostienen una interpretación diversa de la ratio decidendi no están dispuestos a modificar sus preferencias personales en los casos futuros, con la finalidad de asumir un comportamiento precedencial. Con todo, este análisis sólo resulta aplicable a los Ministros propietarios, pues los Ministros suplentes y los abogados integrantes nunca adhirieron a las posiciones de la minoría. Por tanto, a su respecto resulta posible sostener que mantienen un comportamiento precedencial.

Por último, conviene hacer presente que sólo en 4 de las I7 materias de Derecho se encuentran posiciones de minoría. En las otras I 3 materias la ratio decidendi fue adoptada por la unanimidad de la sala del máximo Tribunal.

2. La gran mayoría de los Ministros que no pronunciaron la sentencia en la que se estableció el precedente, aplican la interpretación sostenida por la unanimidad o por la mayoría en los casos posteriores en los que les corresponde intervenir.

Esto ocurre en todos los casos cuando se trata de los 3 Ministros suplentes y de los 16 abogados integrantes que se encuentran en esta situación. Para decirlo en los términos que se evalúan en el presente trabajo, Ministros suplentes y abogados integrantes mantienen un comportamiento perfectamente precedencial. Por su parte, sólo 3 de los I 4 Ministros propietarios que se encuentran en esta situación se apartaron del precedente en una de las materias de Derecho que les correspondió intervenir, pero mantuvieron la interpretación fijada en el precedente en las demás materias.

74. Ricardo Peralta V., abogado integrante. 
3. En definitiva, existe un muy elevado comportamiento precedencial por parte de los Ministros de la Corte Suprema. En el caso de los Ministros titulares y de los abogados integrantes, esta afirmación les resulta plenamente aplicable. En el caso de los Ministros propietarios, generalmente adhieren a la ratio decidendi establecida cuando les corresponde intervenir en los casos posteriores a aquél en que se fijó el precedente. No obstante, mantienen sus preferencias personales fijadas en el voto disidente del caso que fijó dicho precedente.

\section{Referencias}

\section{Libros}

Llewellyng, Karl (1989): The case law system in America. Translate from the German by Michael Ansaldi (Chicago, The University of Chicago Press).

\section{Artículos}

Alchourrón, Carlos (2000): «Sobre Derecho y lógica» (traducido por Jorge L. Rodríguez con la colaboración de Sergio A. Militello), en Isonomía, Instituto Tecnológico Autónomo de México, octubre 2000, número I3, pp. II-33. Disponible en la Word Wide Web: http://www.cervantesvirtual. com/servlet/SirveObras/or 474064433736395354480/index.htm. [Fecha de consulta: 2 de agosto de 2007].

DíAz, L. Iván et al (20I4): «Seguimiento del precedente por la Corte Suprema de Chile en materia laboral. Estudio empírico del recurso de unificación de jurisprudencia». Revista Chilena de Derecho (Pontificia Universidad Católica de Chile), volumen 4I, número 3, septiembre-diciembre de 20I4, pp. IIO5-II3I.

FARBER, Daniel (2006): «The rule of law and the law of precedents», Minnesota Law Review, may 2006, pp. II73-I203.

REHNQUist, James (I986): "Tha power that shall be vested in a precedent: Stare decisis, the Constitutcton and de Supreme Court», Boston University Law Review, march I986, pp. 345-376.

SCHAUER, Frederick (1987): «Precedent», Stanformd Law Review, February I987, pp. 57 I-605.

Soto, Samuel (2013): « ¿Criterios unificados como precedentes judiciales en 
materia laboral?». En Revista de Estudios de la Justicia, número I9, año 20I3, pp. 2I 5-250. Disponible en: http://web.derecho.uchile.cl/cej/docs_2/ SOTO_I 5.pdf. [Fecha de consulta: 6 de julio de 20I 5 ].

\section{Normas legales}

Código Orgánico de Tribunales. Ley 7421, de I943. Disponible en: http:// www.leychile.cl/Navegar?idNorma $=25563$. [Fecha de consulta: 27 de julio de 20I5].

Código de Procedimiento Civil. Ley I552, de I902. Disponible en: http:// www.leychile.cl/Navegar?idNorma=22740. [Fecha de consulta: 29 de julio de 20I5].

Código del Trabajo de Chile, decreto con fuerza de ley $\mathrm{N}^{\circ}$ I, del Ministerio del Trabajo y Previsión Social, 2002, Disponible en: http://www.leychile.cl/ Navegar?idNorma=207436. [Fecha de consulta: 27 de julio de 2015].

\section{Jurisprudencia}

\section{Año 2009}

Fuentealba Candia Lorena con I. Municipalidad San José (2009): Corte Suprema, 27 de octubre de 2009, (recurso de unificación de jurisprudencia, rol 5816-2009).

Lazo con Ilustre Municipalidad de Coquimbo (2009): Corte Suprema, Io de noviembre de 2009 (recurso de unificación de jurisprudencia rol 63352009).

Torres con Ilustre Municipalidad de Coquimbo (2009): Corte Suprema, Io de diciembre de 2009 (recurso de unificación de jurisprudencia rol 678I2009).

Año 2010

Mejías con Municipalidad de Valdivia (2010): Corte Suprema, 3 I de marzo de 2010 (recurso de unificación de jurisprudencia rol 8809-2009).

Saldaña con Interagro Comercio y Ganado S.A. (20I0): Corte Suprema, 8 de abril de 20 io (recurso de unificación de jurisprudencia rol 9265-2009). 
Núñez con Sociedad Contractual Minera Tambillos (2010): Corte Suprema, 20 de abril de 2010 (recurso de unificación de jurisprudencia rol 852-2010). Peralta con Municipalidad de Chiguayante (2010): Corte Suprema, 2 I de abril de 2010 (recurso de unificación de jurisprudencia rol 9024-2009).

Vega con Análisis y Servicios S.A. (2010): Corte Suprema, 2I de abril de 2010 (recurso de unificación de jurisprudencia rol 9603-2009).

Núñez Sonia y Otros con Ilustre Municipalidad de Lanco (2010): Corte Suprema, 22 de abril de 2010 (recurso de unificación de jurisprudencia rol 627-2010).

Alarcón con Municipalidad de San Pedro de la Paz (2010): Corte Suprema, 28 de abril de 2010 (recurso de unificación de jurisprudencia rol 2I 2-2010).

Ayala con Corporación Municipal de Desarrollo Social de Iquique (2010): Corte Suprema, 28 de abril de 20 Io (recurso de unificación de jurisprudencia rol 7930-2009).

Cea y Otros con I. Municipalidad de Coronel (20I0): Corte Suprema, 9 de junio de 2010 (recurso de unificación de jurisprudencia rol I I67-2010).

Machuca con Ilustre Municipalidad de San Pedro de la Paz (2010): Corte Suprema, 9 de junio de 2010 (recurso de unificación de jurisprudencia rol I7I-2010).

Ramírez con Ilustre Municipalidad de Hualpén (2010): Corte Suprema, 9 de junio de 20Io (recurso de unificación de jurisprudencia rol 9I 5-20IO).

Candia con I. Municipalidad de Yumbel (2010): Corte Suprema, I 5 de junio de 2010 (recurso de unificación de jurisprudencia rol I346-2010).

Castro y Otros con Municipalidad de Colbún (2010): Corte Suprema, I 5 de junio de 2010 (recurso de unificación de jurisprudencia rol I984-2010).

Espinosa con I. Municipalidad de Linares (2010): Corte Suprema, I 5 de junio de 2010 (recurso de unificación de jurisprudencia rol 3357-2010).

González con Ilustre Municipalidad de los Ángeles (2010): Corte Suprema, I 5 de junio de 2010 (recurso de unificación de jurisprudencia rol 2975-2010).

Sepúlveda con Ilustre Municipalidad de Talcahuano (2010): Corte Suprema, I 5 de junio de 20 Io (recurso de unificación de jurisprudencia rol I3 I22010).

Uribe y Otro con I. Municipalidad de Paillaco (2010): Corte Suprema, I 5 de junio de 2010 (recurso de unificación de jurisprudencia rol I985-20Io).

Bustamante y Otro con I. Municipalidad de Parral (2010): Corte Suprema, I 6 de junio de 2010 (recurso de unificación de jurisprudencia rol I 584-2010). Pérez y Otros con I. Municipalidad de Mariquina (2010): Corte Suprema, 24 
de junio de 2010 (recurso de unificación de jurisprudencia rol 24I9-2010). Avendaño y Otros con Ilustre Municipalidad de Curepto (2010): Corte Suprema, 29 de junio de 2010 (recurso de unificación de jurisprudencia rol I349-2010).

Ávila y Otros con Ilustre Municipalidad de Parral (2010): Corte Suprema, 29 de junio de 2010 (recurso de unificación de jurisprudencia rol I954-2010). Encina y Otros contra I. Municipalidad de Yerbas (2010): Corte Suprema, 29 de junio de 2010 (recurso de unificación de jurisprudencia rol I 586-2010). Alejandrina con Ilustre Municipalidad de Talca (2010): Corte Suprema, 30 de junio de 2010 (recurso de unificación de jurisprudencia rol I392-2010). Corvalán con Ilustre Municipalidad de Talca (2010): Corte Suprema, 30 de junio de 20Io (recurso de unificación de jurisprudencia rol I345-20I0).

Libis con Municipalidad de Valdivia (2010): Corte Suprema, 30 de junio de 2010 (recurso de unificación de jurisprudencia rol I639-2010).

Lienlaf Marilafy Otras con I. Municipalidad de Mariquina (2010): Corte Suprema, 30 de junio de 2010 (recurso de unificación de jurisprudencia rol 629-2010).

Medel con Ilustre Municipalidad de Talca (2010): Corte Suprema, 30 de junio de 2010 (recurso de unificación de jurisprudencia rol I489-2010).

Rivera con Ilustre Municipalidad de Talca (2010): Corte Suprema, 30 de junio de 2010 (recurso de unificación de jurisprudencia rol I49I-20IO).

San Martín con Ilustre Municipalidad de Talcahuano (2010): Corte Suprema, 30 de junio de 2010 (recurso de unificación de jurisprudencia rol 245420I0).

Agurto y Otros con Ilustre Municipalidad de Canquenes (2010): Corte Suprema, I 3 de julio de 20 Io (recurso de unificación de jurisprudencia rol $3352-2010)$.

Inocencio con I. Municipalidad de Quillota (2010): Corte Suprema, I3 de julio de 2010 (recurso de unificación de jurisprudencia rol 3609-20I0).

Arancibia y Otros con Ilustre Municipalidad de Quillota (2010): Corte Suprema, 28 de julio de 2010 (recurso de unificación de jurisprudencia rol 3488-2010).

Moya con Ilustre Municipalidad de Linares (2010): Corte Suprema, 28 de julio de 2010 (recurso de unificación de jurisprudencia rol 371 8-20I0).

Muena y Otros con Municipalidad de Linares (2010): Corte Suprema, 28 de julio de 20 Io (recurso de unificación de jurisprudencia rol I959-20I0). Concha con Ilustre Municipalidad de Constitución (2010): Corte Suprema, 
4 de agosto de 2010 (recurso de unificación de jurisprudencia rol 25782010).

Silva con Municipalidad de Huechuraba (2010): Corte Suprema, 2 de septiembre de 2010 (recurso de unificación de jurisprudencia rol 399I-2010).

Herrera con Corporación de Desarrollo Social (2010): Corte Suprema, 9 de septiembre de 2010 (recurso de unificación de jurisprudencia rol 38462010).

Aguilera con I. Municipalidad de Curicó (2010): Corte Suprema, I4 de septiembre de 2010 (recurso de unificación de jurisprudencia rol 3358-2010).

Corvera con Ilustre Municipalidad de El Bosque (2010): Corte Suprema, I6 de septiembre de 2010 (recurso de unificación de jurisprudencia rol 329220I0).

Corvera con Ilustre Municipalidad de El Bosque (2010): Corte Suprema, I6 de septiembre de 2010 (recurso de unificación de jurisprudencia rol 329320I0).

Neira con I. Municipalidad de Hualqui (2010): Corte Suprema, I 6 de septiembre de 2010 (recurso de unificación de jurisprudencia rol 30I3-2010).

Lorca y Otros con Ilustre Municipalidad de Arauco (2010): Corte Suprema, 30 de septiembre de 2010 (recurso de unificación de jurisprudencia rol 5062-2010).

Burgos y Otros con I. Municipalidad de Lota (2010): Corte Suprema, I 2 de octubre de 2010 (recurso de unificación de jurisprudencia rol 45 IO-2010).

Villanueva con Fisco de Chile Armada de Chile (2010): Corte Suprema, 26 de octubre de 2010 (recurso de unificación de jurisprudencia rol 5447-2010). Alegría con Laboratorio Koni Cofarm S.A. (2010): Corte Suprema, 28 de octubre de 20Io (recurso de unificación de jurisprudencia rol 4I96-20IO).

Constant y Otros con Ilustre Municipalidad de Lebu (2010): Corte Suprema, 3 de noviembre de 2010 (recurso de unificación de jurisprudencia rol 50 Io2010).

Araneda y Otros con Ilustre Municipalidad de los Álamos (2010): Corte Suprema, 9 de noviembre de 2010 (recurso de unificación de jurisprudencia rol 5833-2010).

Pereira con Consorcio RDTC S.A. (2010): Corte Suprema, Io de noviembre de 2010 (recurso de unificación de jurisprudencia rol 545 I-20IO).

Fuentez y Otros con Ilustre Municipalidad de Lebu (2010): Corte Suprema, I I de noviembre de 2010 (recurso de unificación de jurisprudencia rol 50 I I20IO). 
Bravo con Corporación de Desarrollo I. Municipalidad de la Reina (2010): Corte Suprema, I 5 de noviembre de 2010 (recurso de unificación de jurisprudencia rol 49I I-20IO).

Camaño y Otros con I. Municipalidad de Tomé (2010): Corte Suprema, 23 de noviembre de 2010 (recurso de unificación de jurisprudencia rol 645520I0).

Silva con Corporación de Desarrollo Social de Providencia (2010): Corte Suprema, 26 de noviembre de 20 Io (recurso de unificación de jurisprudencia rol 5835-2010).

Alarcón con Análisis y Servicios S.A, (2010): Corte Suprema, 30 de noviembre de 2010 (recurso de unificación de jurisprudencia rol 6074-2010).

Meza y Otros con Municipalidad de Hualañé (2010): Corte Suprema, 9 de diciembre de 2010 (recurso de unificación de jurisprudencia rol 6763-2010).

Cárcamo con Ilustre Municipalidad de Puerto Montt (2010): Corte Suprema, Io de diciembre de 2010 (recurso de unificación de jurisprudencia rol 5I32-2010).

Añ 2011

Flores y otro con Servicios Prosegur Limitada (20II): Corte Suprema, 6 de enero de 20I I (recurso de unificación de jurisprudencia rol 588I-2010).

Zúniga con Transportes Aéreos del Mercosur S.A. (201 I): Corte Suprema, 26 de enero de 20I I (recurso de unificación de jurisprudencia rol 7362-2010). A.F.P. Provida con Román (201 I): Corte Suprema, 27 de enero de 20 I I (recurso de unificación de jurisprudencia rol 475 I-20IO).

Gómez con ING AFP Capital S.A. (2011): Corte Suprema, 27 de enero de 20I I (recurso de unificación de jurisprudencia rol 60I9-20I0).

Prado con ING AFP Capital S.A. (20 I I): Corte Suprema, 27 de enero de 20 I I (recurso de unificación de jurisprudencia rol 6552-2010).

Morecchio con I. Municipalidad de Tomé (20I I): Corte Suprema, I I de marzo de 20 I I (recurso de unificación de jurisprudencia rol 6936-2010).

Canales y otros con I. Municipalidad de San Rosendo (20I I): Corte Suprema, 23 de marzo de 20 I I (recurso de unificación de jurisprudencia rol 437 I2010).

Valdés con Administradora de Mutuos Hipotecarios del Centro S.A. (20II): Corte Suprema, 24 de marzo de 20 I I (recurso de unificación de jurisprudencia rol 6510-2010). 
Villagrán con Comercial Llanadas S.A. (20I I): Corte Suprema, 24 de marzo de 20I I (recurso de unificación de jurisprudencia rol 7I04-2010).

Reyes con A.F.P. Próvida S.A. (20I I): Corte Suprema, 25 de marzo de 20 I I (recurso de unificación de jurisprudencia rol 6IOI- 20IO).

Cabrera con A.F.P. Próvida S.A. (20I I): Corte Suprema, 28 de marzo de 20 I I (recurso de unificación de jurisprudencia rol 6II4-2010).

Pereira con A.F.P. Próvida S.A. (20I I): Corte Suprema, 28 de marzo de 20 I I (recurso de unificación de jurisprudencia rol 6I I 5-2010).

Ahumada [esta es la carátula que aparece en la página web del Poder Judicial] (20II): Corte Suprema, 29 de marzo de 20 I I (recurso de unificación de jurisprudencia rol 7828-2010).

Cáceres con ING AFP Capital S.A. (20II): Corte Suprema, 29 de marzo de 20I I (recurso de unificación de jurisprudencia rol 6777-2010).

Mora con Municipalidad de Chiguayante (20I I): Corte Suprema, 29 de marzo de 20I I (recurso de unificación de jurisprudencia rol 6973-2010).

Monroy y otra con AFP Hábitat S.A. (2OI I): Corte Suprema, 3 I de marzo de 20I I (recurso de unificación de jurisprudencia rol 6450-20I0).

Solís con Diseño Paisajista (20 I I): Corte Suprema, 3 I de Marzo de 20 I I (recurso de unificación de jurisprudencia rol 7502-2010).

Fernández con Inesa Chile S.A. (20I I): Corte Suprema, I 2 de abril de $20 \mathrm{II}$ (recurso de unificación de jurisprudencia rol 81 55-2010).

Medina con Sistemas Internacionales de Calidad Ltda. y Otro (20I I): Corte Suprema, 29 de abril de 20 I I (recurso de unificación de jurisprudencia rol 8279-2010).

Orellana con Ilustre Municipalidad de El Monte (20I I): Corte Suprema, 29 de abril de 20I I (recurso de unificación de jurisprudencia rol 7I 54-2010).

Córdova con Ilustre Municipalidad de Curicó (20I I): Corte Suprema, I 3 de mayo de 20I I (recurso de unificación de jurisprudencia rol 8859-20I0).

Rencoret y Otro con AFP Provida S.A. (20 I I): Corte Suprema, I 3 de mayo de 20I I (recurso de unificación de jurisprudencia rol 7208-20I0).

Salgado con Toledo y otros (20I I): Corte Suprema, 3 I de mayo de 20 I I (recurso de unificación de jurisprudencia, rol 8316-2010).

Caro y Otros con AFP Provida S.A. (20II): Corte Suprema, 3 de junio de 20I I (recurso de unificación de jurisprudencia rol 6932-2010).

Yáñez con Cúneo (20I I): Corte Suprema, 6 de junio de 20 I I (recurso de unificación de jurisprudencia rol 704-20II).

Araya con Bodega La Esperanza Viñedos Errázuriz Ovalle S.A. (20 I I): Corte 
Suprema, I6 de junio de 20 I I (recurso de unificación de jurisprudencia rol IOI 20-2010).

Soza con Televisión Nacional de Chile (20 I I): Corte Suprema, I 6 de junio de 20I I (recurso de unificación de jurisprudencia rol 205-20II).

Sindicato de Trabajadores de la AFP Provida S.A. con AFP Provida S.A. (20II): Corte Suprema, 29 de junio de 20 I I (recurso de unificación de jurisprudencia rol I I I 7-20II).

Acosta y Otros con Sociedad Depetris Deflorian Hnos. Ltda. (20I I): Corte Suprema, 30 de junio de 20 I I (recurso de unificación de jurisprudencia rol I I6-20II).

Valenzuela con AFP Capital S.A. (20II): Corte Suprema, 8 de julio de 20 I I (recurso de unificación de jurisprudencia rol 8860-2010).

Munizaga con Factor Seguridad Limitada (20I I): Corte Suprema, I de agosto de 20I I (recurso de unificación de jurisprudencia rol 9669-20II).

Vallejos y Otro con Fisco de Chile (20II): Corte Suprema, 8 de agosto de 20I I (recurso de unificación de jurisprudencia rol 8680-20II).

Araya con Monte Nevado Ingeniería y Otros (201 I): Corte Suprema, Io de agosto de 20I I (recurso de unificación de jurisprudencia rol 9375-2010).

Cárdenas con Corporación Municipal de La Florida (20I I): Corte Suprema, 29 de agosto de 2012 (recurso de unificación de jurisprudencia rol I00662OII).

Osses y Otros con AFP Habitat S.A. (201 I): Corte Suprema, 29 de agosto de 20I I (recurso de unificación de jurisprudencia rol 470-20II).

Castillo con Intendencia Regional de la Araucanía (20II): Corte Suprema, 5 de octubre de 20 I I (recurso de unificación de jurisprudencia rol I9722OII).

Tudela con Corporación Municipal de Servicio y Desarrollo de Maipú (20 I I): Corte Suprema, 27 de octubre de 20 I I (recurso de unificación de jurisprudencia rol 70-2011).

Abello con Librería Giorgio Temuco y CIA Limitada (20II): Corte Suprema, I4 de noviembre de 20I I (recurso de unificación de jurisprudencia rol I39I-20II).

Monsalve con Sociedad Educacional Arab \& Perez Ltda. (20I I): Corte Suprema, I 5 de noviembre de 20 I I (recurso de unificación de jurisprudencia rol 3I69-2OII).

Cabello con Cáceres (20I I): Corte suprema, I7 de noviembre de 20 I I (recurso de unificación de jurisprudencia rol 3488-201 I). 
Berríos con Pullman cargo (20I I): Corte Suprema, 6 de diciembre de 20 I I (recurso de unificación de jurisprudencia rol 3I68-20II).

Boasso con Rosa (20 I I): Corte Suprema, I 5 de diciembre de 20 I I (recurso de unificación de jurisprudencia rol 4584-20I I).

Dussuel con Colegio San Bartolomé De Nos S.A. (20I I): Corte Suprema, 3 I de enero de 2012 (recurso de unificación de jurisprudencia rol 5964-20II). Alarcón con Administradora de Fondos de Pensiones Capital S.A. (2011): Corte Suprema, I 6 de diciembre de 20 I I (recurso de unificación de jurisprudencia rol I863-20II).

Sindicato Unificado de Trabajadores de Isapre Banmédica S.A. con Isapre Banmédica S.A. (20I I): Corte Suprema, I 6 de diciembre de 20 I I (recurso de unificación de jurisprudencia rol 2739-20II).

Año 2012

Rodríguez con Inversiones Alsacia S.A, (2012): Corte Suprema, 27 de enero de 2012 (recurso de unificación de jurisprudencia rol 4735-20II).

Campos y Otros con Empresa de Montajes Industriales Salfa S.A. (2012): Corte Suprema, 30 de enero de 2012 (recurso de unificación de jurisprudencia rol 4259-20II)..

Gallardo con Red Capacita S.A. (2012): Corte Suprema, 24 de abril de $20 \mathrm{I} 2$ (recurso de unificación de jurisprudencia rol 5843-20II).

Suazo con Fisco De Chile, Ministerio Secretaría General De Gobierno (2012): Corte Suprema, 25 de abril de 2012 (recurso de unificación de jurisprudencia rol 5839-20II).

Aravena y Otros con VTR Global Com S.A. (2012): Corte Suprema, I7 de mayo de 20I2 (recurso de unificación de jurisprudencia rol 8788-20II).

Contreras con Fondo De Solidaridad e Inversión Social (2012): Corte Suprema, 25 de mayo de 2012 (recurso de unificación de jurisprudencia rol 8II8-20II).

Gonzáles y Otros con AFP Provida S.A. (20I2): Corte Suprema, 6 de junio de 2012 (recurso de unificación de jurisprudencia rol 8322-20II).

Campusano con AFP Planvital S.A, (2012): Corte Suprema, 8 de junio de $20 \mathrm{I} 2$ (recurso de unificación de jurisprudencia rol 8504-20II).

Caro con Envases Del Pacífico S.A. (2012): Corte Suprema, I4 de junio de 2012 (recurso de unificación de jurisprudencia rol 9242-20II).

Ramírez Y Otros con Liceo Comercial Gabriela Mistral (2012): Corte Su- 
prema, 22 de junio de 2012 (recurso de unificación de jurisprudencia rol 8488-2OI I).

Hidalgo con Corporación De Fomento De La Producción (2012): Corte Suprema., 27 de junio de 20 I 2 (recurso de unificación de jurisprudencia rol 5544-20I I).

Peralta con Corporación Municipal De Edu. Salud y Atenc. De Menores De Puente Alto (2012): Corte Suprema, 3 de agosto de 2012 (recurso de unificación de jurisprudencia rol I0266-20II).

Parada con AFP Capital S.A. (2012): Corte Suprema, 8 de agosto de 2012 (recurso de unificación de jurisprudencia rol I07I3-20I I).

Kerbernhard con Recaudación y Cobranzas S.A. (2012): Corte Suprema, 9 de agosto de 20 I 2 (recurso de unificación de jurisprudencia rol 9579-20I I). Azocar con Sociedad Comercial Wingel Ltda. (2012): Corte Suprema, Io de agosto de 20 I 2 (recurso de unificación de jurisprudencia rol 9838-20I I). Marambio con Liceo Comercial Gabriela Mistral (2012): Corte Suprema, I7 de agosto de 2012 (recurso de unificación de jurisprudencia rol 88922OII)..

Soto con Colegio Misionero de Agostini (2012): Corte Suprema, I 7 de agosto de 2012 (recurso de unificación de jurisprudencia rol i i 875-20 I I).

Becker con Premium Nutregg S.A. (2012): Corte Suprema, 2 I de agosto de 2012 (recurso de unificación de jurisprudencia rol 36I-20I2).

Loyola con Compass Catering S.A. (2012): Corte Suprema, 2 I de agosto de 2012 (recurso de unificación de jurisprudencia rol 208-20I2).

Irazzoky con Comercial Rey S.A. (2012): Corte Suprema, 24 de agosto de 20I 2 (recurso de unificación de jurisprudencia rol I I 873-20I I).

Ponce con Distribuidora de Industrias Nacionales S.A DIN (2012): Corte Suprema, 24 de agosto de 2012 (recurso de unificación de jurisprudencia rol I I 65 5-20I I)..

Orrego con Empresa Periodística La Cuarta S.A. (2012): Corte Suprema, 29 de agosto de 20I2 (recurso de unificación de jurisprudencia rol 8989-20I I). Espinoza con Fisco de Chile, Ministerio Secretaría General de la República (2012): Corte Suprema, 30 de agosto de 2012 (recurso de unificación de jurisprudencia rol 462-2012).

Domke con Ilustre Municipalidad de Puerto Montt (2012): Corte Suprema, 3 I de agosto de 2012 (recurso de unificación de jurisprudencia rol Io87I2OII).

Bravo y Otros con Ilustre Municipalidad de Osorno (2012): Corte Suprema, 6 
de septiembre de 2012 (recurso de unificación de jurisprudencia rol 80352OII).

Parra y Otros con Ilustre Municipalidad de Temuco (201 2): Corte Suprema, 6 de septiembre de 2012 (recurso de unificación de jurisprudencia rol $787 \mathrm{I}$ 2OII).

Aguirre con Corporación Municipal de Desarrollo Social de Antofagasta (20I2): Corte Suprema, I 2 de septiembre de 2012 (recurso de unificación de jurisprudencia rol 589-2012).

Cutiño con Ilustre Municipalidad de Puerto Aysén (201 I): Corte Suprema, 26 de septiembre de 20I2 (RUJ rol 8780-20II).

Gasca con Zuñiga (20I2): Corte Suprema, 3 de octubre de $20 \mathrm{I} 2$ (recurso de unificación de jurisprudencia rol I27I2-20II).

Véliz con TP Chile S.A. (2OI2): Corte Suprema, I 2 de octubre de 20 I 2 (recurso de unificación de jurisprudencia rol 820-20I2).

Castillo con Jara (20I2): Corte Suprema, 23 de octubre de 2012 (recurso de unificación de jurisprudencia rol I I70-20I2).

Moya con Ilustre Municipalidad de Frutillar (2012): Corte Suprema, 7 de noviembre de 20I 2 (recurso de unificación de jurisprudencia rol I 225 I-20II).

Olivares con Pontificia Universidad Católica de Chile (2012): Corte Suprema, 28 de noviembre de 2012 (recurso de unificación de jurisprudencia rol

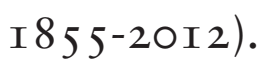

Riquelme con Pontificia Universidad Católica de Chile Corporación de Televisión (20I2): Corte Suprema, 28 de noviembre de 20 I 2 (recurso de unificación de jurisprudencia rol I68I-20I2).

Pereira con Ilustre Municipalidad de San Esteban (20I2): Corte Suprema, 2 I de diciembre de 2012 (recurso de unificación de jurisprudencia rol 26582OI2)..

Castillo con Bahamonde y Cia Ltda. (2012): Corte Suprema. 28 de diciembre de 20I2 (recurso de unificación de jurisprudencia rol 2500-20I2).

Poblete y Otros con Corporación de Desarrollo de la comuna de San Vicente de Tagua Tagua (2012): Corte Suprema, 28 de diciembre de 2012 (recurso de unificación de jurisprudencia rol 2506-2012).

Año 2013

Contreras con Ilustre Municipalidad de Puerto Montt (2013): Corte Suprema, I I de abril de 20I3 (recurso de unificación de jurisprudencia rol 2I 54-20I2). 